\title{
Reduction of jaw opening (trismus) in giant cell arteritis
}

\author{
R Nir-Paz, A Gross, T Chajek-Shaul
}

Ann Rheum Dis 2002;61:832-833

Objective: To study the prevalence and the clinical characterisation of jaw problems in patients with giant cell arteritis (GCA).

Methods: the prevalence of such symptoms in patients with GCA was evaluated by performing a retrospective analysis of all patients with GCA and polymyalgia rheumatica who were diagnosed during admission to Hadassah University Hospital. Ten patients reported previously in the literature were also evaluated.

Results: Six patients out of $88(6.8 \%)$ had complaints of reduction in jaw opening. These six patients seemed to have a much more abrupt onset of disease with shorter duration until diagnosis, higher prevalence of eye involvement $(50 \% \vee 27 \%)$, and a higher rate of positive pathology $(100 \%)$

Conclusions: Reduction in jaw opening in the appropriate setting may indicate the presence of GCA. This sign should not be overlooked in the presence of the claudication sign as it seems to reflect more severe GCA disease.

G iant cell arteritis (GCA) is a relatively common disease among elderly people in western communities. ${ }^{1}$ The disease presents in most patients after the age of 60 . Common complaints include non-specific signs such as fatigue, fever, headache, and muscle and girdle pains. These non-specific complaints in combination with the age of the patients and results from a few simple laboratory tests (such as increased erythrocyte sedimentation rate (ESR), serum alkaline phosphatase, and thrombocytosis) lead to the tentative diagnosis of GCA. The diagnosis is confirmed in most patients by a positive biopsy specimen from the temporal artery. In some patients other more unusual presentations can occur, leading to the delayed diagnosis of GCA and, at times, resulting in devastating complications, such as blindness. Sonnenblick et al have reviewed some of these rare presentations. $^{2}$

Claudication of the jaw is considered a common manifestation of the disease and is reported in about $40 \%$ of patients. ${ }^{3-6}$ Some of these patients present initially to their dentist or oral surgeon.

A perusal of the case reports described by Crosby and Wadsworth in the first review on GCA in the literature showed that two of the patients had a reduction in the ability to open their mouth. ${ }^{7}$ This sign—-trismus-has since been reported only rarely in the literature in conjunction with GCA. Also, GCA is not mentioned in textbooks discussing the differential diagnosis of this sign.

In this paper we report the prevalence of trismus in patients with GCA admitted to hospital. We also examine the particular clinical features of patients with GCA presenting with trismus.

\section{METHODS}

We retrospectively reviewed the computerised database of the Hadassah University Hospitals (Jerusalem, Israel) for all patients with the diagnosis of GCA or polymyalgia rheumatica (PMR) between 1 January 1980 and 31 December 1998. A total of 143 patients were diagnosed as having GCA and 101 were diagnosed with PMR. All files were then reviewed for patients in whom the diagnoses of either GCA or PMR were made during their stay in hospital. Only patients whose diagnosis in hospital fulfilled the criteria of the American College of Rheumatology in 1990 for GCA, ${ }^{8}$ and Bird's criteria for PMR were included in the study. ${ }^{9}$ A total of 88 patients were eligible-59 (67\%) women and $29(33 \%)$ men-of whom only $15(25 \%)$ and two (7\%) respectively were diagnosed with PMR. Patients were excluded if the diagnosis was made out of hospital, or if the diagnostic criteria mentioned above were not met.

\section{RESULTS}

Over a period of 18 years 88 patients were diagnosed in our hospitals as having GCA or PMR. Six out of these $88(6.8 \%)$ patients had reduced ability to open their mouths. At least two out of the six were examined for this complaint. The mouth opening width was found for both of them to be less than $3 \mathrm{~cm}$ ( 2.8 and $2.3 \mathrm{~cm}$, measured with a ruler between the teeth). For the other four patients such measurements were not documented in the medical records. Table 1 presents the clinical characteristics for these six patients. Ten additional cases have been described in the literature. ${ }^{70-16}$ Table 1 also summarises their characteristics. In patients with trismus, the time from the beginning of the symptoms to the diagnosis of the disease was shorter than that of our group (4-6 weeks $v 12$ days). Eye involvement occurred in about half of them compared with $25 \%$ in our group. All of them had positive pathology compared with $86 \%$ of the patients with GCA. Jaw involvement occurred in $6 / 88(6.8 \%)$ of our patients but claudication was only reported in $9 / 88(10 \%)$. In all other clinical features (such as age, headache, fever and laboratory results) the patients with trismus and GCA did not seem to differ from other patients with GCA. The response of the trismus to corticosteroid therapy was evident within one to four days, at the same rate as all other symptoms and signs of GCA (table 1).

A typical case report is presented here. A 62 year old male construction worker was referred with two weeks of inability to open his mouth accompanied by pain in his legs. Antibiotic treatment with amoxycillin was started for presumed pharyngeal infection. The patient developed a fever and was admitted to hospital where amoxycillin was stopped. The patient had no medical history and denied smoking or drinking alcohol. Physical examination was unremarkable except for mild tenderness in his thighs and very limited opening of his mouth $(23 \mathrm{~mm})$. His oral hygiene was notably poor. His laboratory tests showed an increased ESR and a mildly increased white blood count $\left(13.5 \times 10^{9} / 1\right)$. All other tests performed, including

Abbreviations: GCA, giant cell arteritis; ESR, erythrocyte sedimentation rate; PMR, polymyalgia rheumatica 
Table 1 Characteristics of patients with GCA and reduction in jaw opening

\begin{tabular}{|c|c|c|c|}
\hline & $\begin{array}{l}\text { Our series of } \\
\text { patients with } \\
\text { trismus }\end{array}$ & $\begin{array}{l}\text { All patients } \\
\text { with trismus } \\
\text { (ours and } \\
\text { literature) }\end{array}$ & $\begin{array}{l}\text { All patients } \\
\text { with GCA }\end{array}$ \\
\hline Age & $72.2(5.2)$ & 70 (5.7) & $71.6(8.8)$ \\
\hline $\operatorname{Sex} M / F$ & $1 / 5$ & $5 / 11$ & $29 / 59$ \\
\hline Symptoms (weeks) & $5.9(4.2)$ & $4.3(4)$ & $12.35(17.4)$ \\
\hline Jaw claudication & $2 / 6$ & $4 / 16$ & $9 / 88$ \\
\hline Opening width & $2.4 ; 2.6^{*}$ & $2.0(0.5)$ & \\
\hline Eye involvement & $3 / 6$ & $8 / 16$ & $24 / 88$ \\
\hline Headache & $5 / 6$ & $12 / 15$ & $56 / 88$ \\
\hline Fever & $38.2(0.8)$ & $38.2(0.6)$ & $37.52(0.9)$ \\
\hline Muscle pain in legs & $3 / 6$ & $4 / 9$ & \\
\hline $\begin{array}{l}\text { Erythrocyte } \\
\text { sedimentation rate }\end{array}$ & $90(40)$ & $99.8(35)$ & 103 (31) \\
\hline Platelets & 381 (127) & $388(105)$ & 405 (127) \\
\hline Alkaline & & & \\
\hline phosphatase & $103(46)$ & $134(93.8)$ & $122(104)$ \\
\hline Positive pathology & $6 / 6$ & $14 / 14$ & $61 / 77$ \\
\hline Days to recovery & $3.2(1.6)$ & $2.5(1.4)$ & $4.1(3.9)$ \\
\hline
\end{tabular}

multiple cultures, total body computed tomography, and bone marrow aspiration, were unremarkable. A biopsy of the temporal artery showed GCA. Steroid treatment was started, with improvement of the patient's complaints within less than 24 hours, including resolution of his trismus. The mouth opening width measured with a ruler between the teeth, at 24 hours and three months after therapy initiation, was $40 \mathrm{~mm}$.

\section{DISCUSSION}

Jaw claudication is a very common symptom in patients with temporal arteritis. ${ }^{3-6}$ Some of these patients also complain about other symptoms related to the jaw such as reduction in the opening of the mouth. This sign, although considered very rare and described mainly in case reports, was found in our series to be relatively common, with a prevalence of $6.8 \%$. This may be an underestimate due to underreporting of this complaint in patients' charts; owing to the lack of physicians' awareness the complaint may easily be confused with the more common complaint of claudication. Evidence for this is found in another series from Israel, which reported that prevalence of claudication is about $20 \%,{ }^{17}$ a number that compares well with the total number of patients with jaw involvement in our series, of whom only half had true claudication. Our series is hospital based and, as such, may have its own bias. Therefore, it does not necessarily reflect the course of disease that is managed on an outpatient basis.

It seems that patients with GCA and trismus have a more aggressive form of the disease. This is manifested by the relatively high rate of eye involvement $(50 \%$ in patients and those in the literature) and the markedly shorter duration of symptoms until diagnosis (four weeks compared with 12 weeks in the patients with GCA). This implies that the trismus sign reflects a more aggressive form of GCA. The data were not assessed for statistically significant differences because of the few cases in our series and because the patients described in the literature were collected over more than half a century and from different populations. Such calculations should be done in future cohort studies on GCA and jaw involvement.

It is important for all physicians, including dentists, to be aware of both claudication and reduction in jaw opening as potential symptoms of GCA, a disease with devastating consequences, such as blindness, if not treated promptly.

We conclude that the occurrence of relatively acute jaw reduction in an elderly patient with headache should alert for the diagnosis of GCA, and should prompt a thorough investigation, including a temporal artery biopsy, and consideration of steroid use to prevent the devastating complication of visual loss.

\section{Authors' affiliations}

R Nir-Paz, T Chajek-Shaul, Department of Medicine, Hadassah

University Hospital, Jerusalem, Israel

A Gross, Department of Oral Medicine

Correspondence to: Dr Tova Chajek-Shaul, Department of Medicine, Hadassah University Hospital, Mount Scopus, PO Box 24035, Jerusalem 91240, Israel; chajek@hadassah.org.il

Accepted 6 March 2002

\section{REFERENCES}

1 Evans JM, Hunder GG. Polymyalgia rheumatica and giant cell arteritis. Rheum Dis Clin North Am 2000;26:493-515.

2 Sonnenblick M, Nesher G, Rosin A. Non-classical organ involvement in temporal arteritis. Semin Arthritis Rheum 1989;19:183-90.

3 Duhaut P, Pinede L, Bornet H, Demolombe-Rague S, Dumontet C, Ninet $J$, et al. Biopsy proven and biopsy negative temporal arteritis: differences in clinical spectrum at the onset of the disease. Groupe de Recherche sur I'Arterite a Cellules Geantes. Ann Rheum Dis 1999:58:335-41.

4 Gonzalez-Gay MA, Blanco R, Sanchez-Andrade A, Vazquez-Caruncho $M$. Giant cell arteritis in Lugo, Spain: a more frequent disease with fewer classic features. J Rheumatol 1997;24:2166-70.

5 Liozon E, Herrmann F, Ly K, Robert P, Loustaud V, Soria P, et al. Risk factors for visual loss in giant cell (temporal) arteritis: a prospective study of 174 patients. Am J Med 2001;111:211-7.

6 Myklebust G, Gran JT. A prospective study of 287 patients with polymyalgia rheumatica and temporal arteritis: clinical and laboratory manifestations at onset of disease and at the time of diagnosis. $\mathrm{Br} \mathrm{J}$ Rheumatol 1996;35:1161-8.

7 Crosby RC, Wadsworth RC. Temporal arteritis: review of the literature and report of five additional cases. Arch Intern Med 1948;81:431-4.

8 Hunder GG, Bloch DA, Michel BA, Stevens MB, Arend WP, Calabrese $\mathrm{LH}$, et al. The American College of Rheumatology 1990: criteria for the classification of giant cell arteritis. Arthritis Rheum 1990;33:1 122-8.

9 Bird HA, Esselinckx W, Dixon AS, Mowat AG, Wood PH. An evaluation of criteria for polymyalgia rheumatica. Ann Rheum Dis 1979;38:434-9.

10 Chevalet P, Pineau A, Elkouri D, Taugeron F, Le Strat A, Magadur-Joly $G$, et al. Trismus disclosing Horton's disease. Rev Stomatol Chir Maxillofac 1996:97:350-1.

11 Delvigne JM, Piette AM, Chapman A. Horton's disease disclosed by trismus. Presse Med 1985;14:1151-2.

12 Desser EJ. Miosis, trismus and dysphagia. An unusual presentation of temporal arteritis. Ann Intern Med 1969;71:961-2.

13 Henriet JP, Letellier P, Agron L, Pelouze G, Maiza D, Evrard C. Horton's disease disclosed by trismus. Role of the involvement of the internal maxillary arteries. Presse Med 1985; 14:2109.

14 Manganelli P, Malvezzi L, Saginario A. Trismus and facial swelling in a case of temporal arteritis. Trismus and facial swelling in a case of temporal arteritis. Clin Exp Rheumatol 1992;10:102-3.

15 Taillan B, Fuzibet JG, Verdier JM, Castela J, Vinti H, Dujardin P. Horton's disease revealed by a trismus: two new cases. Rev Rheum Mal Osteoartic 1988;55:955-6.

16 Taillandier J, Alemanni M, Manigand G. Horton's disease disclosed by trismus. Presse Med 1987; 16:911.

17 Nesher G, Gur H, Ehrenfeld M, Rubinow A, Sonnenblick M. The changing clinical presentation of temporal arteritis in Israel: A multicenter study. Isr Med Assoc J 1999; 1:17-9 